\title{
Cigarette smoking and risk of gestational diabetes: a systematic
} review of observational studies

\author{
Eliana M Wendland*1, Maria Eugênia Pinto ${ }^{1}$, Bruce B Duncan ${ }^{1}$, \\ José M Belizán² and Maria Inês Schmidt ${ }^{1}$
}

\author{
Address: ${ }^{1}$ Graduate Studies Program in Epidemiology, Faculty of Medicine, Federal University of Rio Grande do Sul, Porto Alegre, Brazil and \\ ${ }^{2}$ Department of Mother \& Child Health Research, Institute for Clinical Effectiveness and Health Policy (IECS), Buenos Aires, Argentina \\ Email: Eliana M Wendland* - eliana.wendland@ufrgs.br; Maria Eugênia Pinto - meugeniap@terra.com.br; \\ Bruce B Duncan - bbduncan@orion.ufrgs.br; José M Belizán - belizanj@allstat.org; Maria Inês Schmidt - mschmidt@adufrgs.ufrgs.br \\ * Corresponding author
}

Published: 16 December 2008

BMC Pregnancy and Childbirth 2008, 8:53 doi:10.1186/147I-2393-8-53

This article is available from: http://www.biomedcentral.com/I47/-2393/8/53

(c) 2008 Wendland et al; licensee BioMed Central Ltd.

This is an Open Access article distributed under the terms of the Creative Commons Attribution License (http://creativecommons.org/licenses/by/2.0), which permits unrestricted use, distribution, and reproduction in any medium, provided the original work is properly cited.
Received: 26 March 2008

Accepted: 16 December 2008

\begin{abstract}
Background: Gestational diabetes is a prevalent disease associated with adverse outcomes of pregnancy. Smoking as been associated with glucose intolerance during pregnancy in some but not all studies. Therefore, we aimed to systematically review all epidemiological evidence to examine the association between cigarette smoking during pregnancy and risk of developing gestational diabetes mellitus.
\end{abstract}

Methods: We conducted a systematic review of articles published up to 2007, using PubMed, Embase, LILACS e CINAHL to identify the articles. Because this review focuses on studies of smoking during pregnancy, we excluded studies evaluating smoking outside pregnancy. Two investigators independently abstracted information on participant's characteristics, assessment of exposure and outcome, and estimates for the association under study. We evaluated the studies for publication bias and performed heterogeneity analyses. We also assessed the effect of each study individually through sensitivity analysis.

Results: We found and critically reviewed 32 studies, of which 12 met the criteria for inclusion in the review. Most of the studies provided only unadjusted measurements. Combining the results of the individual studies, we obtained a crude odds ratio of $\mathrm{I} .03(99 \% \mathrm{Cl} 0.85-1.25)$. Only 4 studies presented adjusted measurements of association, and no association was found when these alone were analyzed (OR 0.95; $99 \% \mathrm{Cl} 0.85-1.07)$. Subgroup analysis could not be done due to small sample size.

Conclusion: The number of studies is small, with major heterogeneity in research design and findings. Taken together, current data do not support an association between cigarette smoking during pregnancy and the risk of gestational diabetes.

\section{Background}

Gestational diabetes mellitus (GDM) is defined as glucose intolerance with onset or first recognition during preg- nancy [1], and affects 1 to $15 \%$ of all pregnancies overall [2] and 7.6\% of pregnancies in Brazil [3]. The prevalence of gestational diabetes mellitus varies in direct proportion 
with the prevalence of type 2 diabetes and is increasing over time along with the prevalence of obesity [4]. Its onset is associated with increased rates of macrosomia which in turn increases the risk of cesarean section, shoulder dystocia and birth trauma $[3,5,6]$. A long-term consequence of gestational diabetes for the mother is increased risk of progression to type 2 diabetes later in life $[7,8]$.

Many predisposing factors, such as advanced age, obesity, non-Caucasian ethnicity, and family history of type 2 diabetes have been associated with an increased risk of gestational diabetes $[9,10]$. Previous gestational diabetes, unexplained fetal loss or newborns large for gestational age have also been linked to an increased risk of gestational diabetes mellitus [11].

Although a tendency of reduction in the number of women who smoke during pregnancy has been observed [12], cigarette smoking is still common during pregnancy [13-16]. Smoking during pregnancy has been associated with short and long term adverse outcomes including premature rupture of fetal membranes, placenta previa, placental abruption [17], preterm delivery [18], and future childhood obesity and hypertension [19]. Increased insulin resistance $[20,21]$, hyperinsulinemia and type 2 diabetes have been linked with cigarette smoking outside of pregnancy in some but not all studies $[18,22]$, but whether cigarette smoking is a risk factor for the development of gestational diabetes remains controversial $[23,24]$. Intriguingly, smoking has been negatively associated with pre-eclampsia [25] and, more recently, outside of pregnancy, with reduced risk of some gastrointestinal diseases [26] and Parkinson's disease [27].

Given this uncertainty about the relationship between smoking in pregnancy and GDM, the aim of this study is to systematically review all epidemiological evidence on the relation between smoking habits during pregnancy and risk of gestational diabetes mellitus.

\section{Methods}

A specific protocol was designed for this systematic review, which was reported in accordance with the checklist proposed by the Meta-analysis of Observational Studies in Epidemiology (MOOSE) group [28].

\section{Search strategies}

We searched for published and unpublished studies reported from 1970 to 2006 in PubMed http:// www.ncbi.nlm.nih.gov. The electronic search strategy was constructed using the key terms suggested by the Metabolic and Endocrine Disorders Group [29], Pregnancy and Childbirth Group [30] and Tobacco Addiction Group [31]: "smoke" or "smoking" or "tobacco use" or "cigarette" combined with "gestational diabetes" or ("diabe- tes" and "pregnancy") in text words or medical subject headings. We used similar strategies to search LILACS (Latin America and Caribbean database), EMBASE and CINAHL. Additionally, to avoid publication bias, we did a broader search, generically using the term "risk factor", looking for articles in which smoking was not necessarily the primary exposure. We manually searched reference lists of retrieved articles and of relevant reviews, as well as web pages of selected ministries of health and other potentially relevant internet sources. No attempt was made to contact the authors of any of these studies in order to get primary data. We restricted our search to studies of humans, with no language restrictions.

\section{Criteria for considering studies}

We considered all observational studies that assessed the association between smoking cigarettes during pregnancy and gestational diabetes, and which provided adjusted or crude relative risks (RR), odds ratios (OR) or information that enabled us to calculate the crude measures of association. The diagnosis of gestational diabetes had to be obtained by an oral glucose tolerance test (OGTT) or by a clinical diagnosis. We excluded studies of type 1 diabetes, reports of tobacco products other than cigarettes, animal studies and case series. Studies not having a clear statement that smoking occurred during pregnancy, not having exposure measured before the outcome, or not having a clear definition of the diagnostic process for the outcome were not included.

\section{Study selection and data extraction}

Titles and abstracts of the resulting publications were screened for articles of possible interest by two independent investigators (E.M.W. - obstetrician and M.E.P. - primary care physician). When the information provided by the title and abstract was not sufficient to determine exclusion, we evaluated the full-text. For data extraction, we adapted a form recommended by Cochrane Non-Randomized Studies Methods Group [32]. Two investigators independently abstracted information on participant characteristics, measurements of smoking habits and outcomes, adjustment for potential confounders, and estimates of association. Discrepancies were resolved by discussion and repeated examination of the articles and, when necessary, through consultation of a third author (M.I.S.).

\section{Appraisal of methodological quality of primary studies}

All articles meeting the eligibility criteria were assessed for their methodological quality by two independent investigators (E.M.W. and M.E.P). This assessment involved scrutinizing study design, sampling method, source of data and definition of exposure and diagnostic procedures. The presence of clear definitions of exposure and diagnostic methods were regarded as an indication of higher quality. 


\section{Data synthesis and statistical analysis}

We used MIX - Meta-analysis with Interactive Explanations (version 1.54) [33] for all statistical analyses. When an unadjusted odds ratio (OR) for smoking - gestational diabetes mellitus association was not provided in the manuscript, we manually calculated it from the data provided. Data input was double-checked for accuracy, and the ORs calculated by MIX were compared to the ORs reported in the original studies.

Combination of results involved inverse-varianceweighted averages of the log odds ratio $[\ln (\mathrm{OR})]$. Initially, the overall association was calculated using a MantelHaenzel fixed-effects model. Heterogeneity was assessed using Cochran's Q test. As this test is considered to have low statistical power, especially when the number of studies included in the meta-analysis is small $(<20)$, a random effect model (DerSimonian-Laird) was used if the $P$-value was less than 0.1 [34]. Confidence intervals of $99 \%$ were used for individual and overall associations to allow for the increased possibility of random error in multiple comparisons. Meta-analysis was applied to crude odds ratios, and, when available, additionally to adjusted odds ratios. Degree of adjustment for potential confounders were categorized as "+" for age; "++" for age plus BMI; "+++" for these plus weight gain during pregnancy.

Publication bias was evaluated quantitatively using Egger's regression, in which the standardized effect estimates are regressed against estimated precision [35]. We did not employ graphical methods such as the funnel plot as this technique requires a larger number of studies to provide an adequate graph [36]. To investigate the impact of the control for confounding factors on the study estimates, we grouped the studies according with the presence or absence of adjustments.

In addition, to evaluate the stability of the results of this meta-analysis and to explore the effect of heterogeneity in studies, we also performed a one-way sensitivity analysis. By removing one study at a time and recalculating the odds ratio, we observed the effect of each study on the summary estimate, thus evaluating the robustness of the results [35]. When possible, additional meta-analyses were performed on relevant sub-groups of studies to investigate possible causes of heterogeneity.

\section{Results}

We initially identified 1439 references, 1354 in Medline, 68 in EMBASE, 9 in LILACS and 8 in CINAHL. After exclusions determined by abstract review, 32 studies were considered. Of these, we excluded an additional 20 studies, 12 thus remaining for the systematic review (Figure 1). These exclusions were due to not assessing smoking during pregnancy [37]; not having a clear definition of the diagnostic process [38-43] or diagnosing GDM with intravenous tolerance testing $[44,45]$; lacking sufficient information to calculate measures of association [46-48]; not providing primary data [49]; not ascertaining GDM [5055]; or not assessing the exposure before the outcome [56].

Table 1 shows selected characteristics of the studies analyzed. Two studies that investigated the same study population [24,57], but with somewhat different sample size and results, were included. All studies that provided adjusted measurements included age in the analysis.

As shown in Additonal File 1, universal and selective screening (or both) for gestational diabetes was used. Four studies used the 2-h OGTT (WHO definition), seven used the 3-h OGTT (ADA definition), one used more than one criteria for diagnosis of GDM and another used the ICD-code for gestational diabetes. Studies varied in their classification of smoking status. For example, some separated women who quit smoking before and during pregnancy. Others pooled all women who smoked any cigarette during pregnancy. Only three studies provided measurements of association for different smoking categories [23,24,58]. All studies were based on self-report of smoking. None of the studies evaluated in this systematic review provided information about the type of cigarettes smoked.

As significant heterogeneity between studies was found in the meta-analysis of the nine $[24,57,59-65]$ reports of crude associations $(\mathrm{Q}=50.14 ; \mathrm{p}<0.01)$, we used a random effects method for this analysis (Figure 2). No association between smoking during pregnancy and GDM was present in such analysis, the summary unadjusted OR being 1.03 (99\% CI 0.85-1.25).

Only four studies, including five distinct populations, described adjusted odds ratios and assessed potential confounders when non smokers were compared to current smokers $[24,59,66,67]$. As heterogeneity between studies did not reach statistical significance in the adjusted metaanalysis $(\mathrm{Q}=7.0 ; \mathrm{p}=0.14)$, we used a fixed effects model. Combining the adjusted results produced an overall odds ratio of 0.95 (99\% CI $0.85-1.07 ; \mathrm{p}=0.27$ ) (Figure 3). Since the native Cree Canadian population has a high prevalence of gestational diabetes [68], we conducted a sensitivity analysis excluding this population; only minimal changes were found in the summary measurement $(\mathrm{OR}=0.97 ; 95 \%$ CI 0.69-1.38). Sub-group analysis by type of diagnostic criteria (3-hour OGTT versus 2-h OGTT), did not reveal important differences. Additional sub-group analysis by gestational age of smoking assessment showed that when smoking was assessed at less than 24 weeks of pregnancy $[24,57,62,63,65]$, the combined 


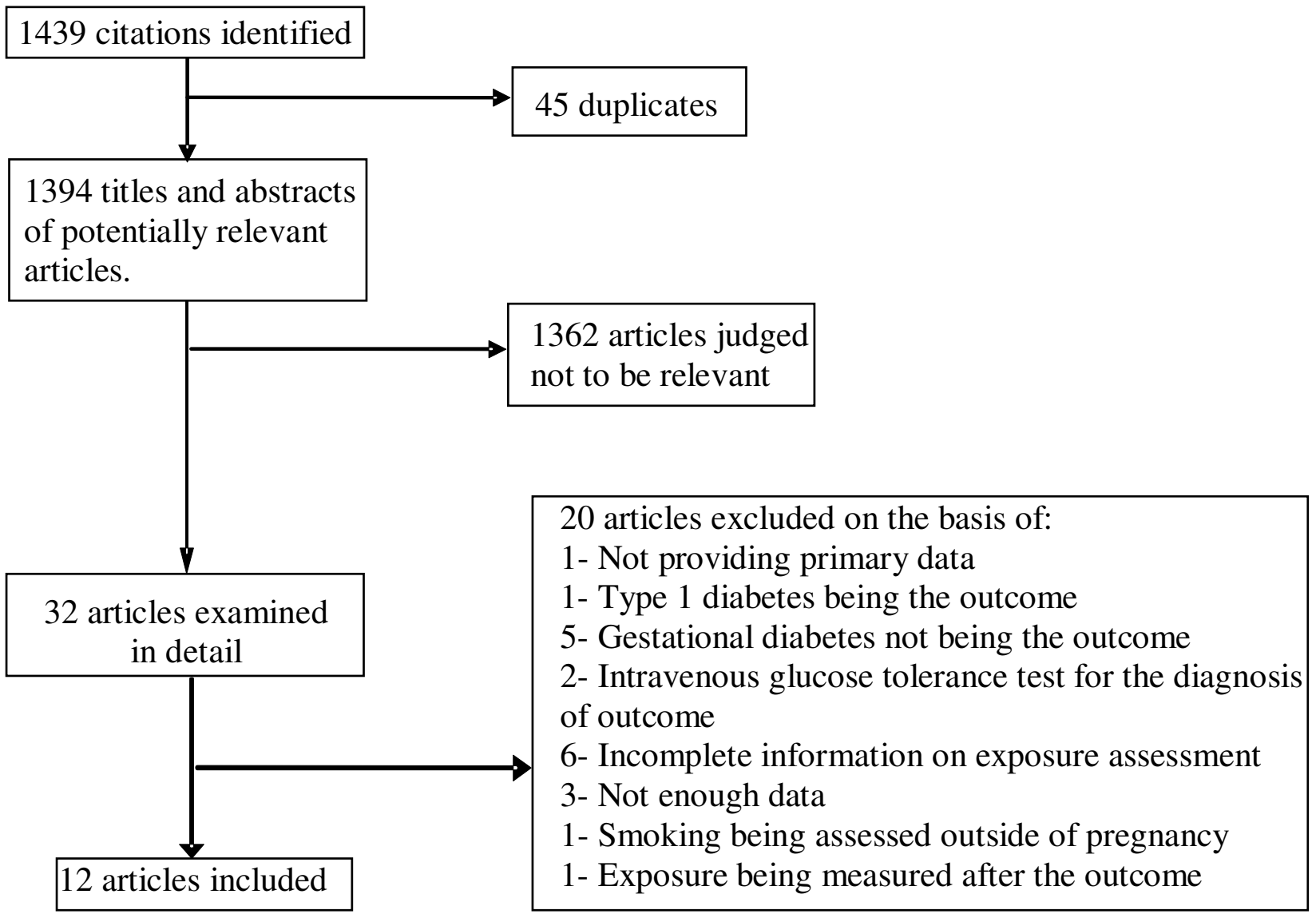

Figure I

Flow diagram of the study selection process summarizing study assessment and exclusion stages.

crude OR, using a random effects model, was $1.22(99 \%$ CI 0.73-2.04), whereas when smoking was assessed at later than 24 weeks $[59,61,64,69]$, it was 0.88 (99\% CI 0.70-1.10).

We identified three studies, assessing different levels of smoking [23,24,70] (Additonal File 1). A fixed effects analysis showed no association of light smoking (1-9 cig/ day) with GDM (OR = 0.94; 99\% CI 0.83-1.06), without heterogeneity between studies $(\mathrm{Q}=4.25$; $\mathrm{p}=0.24)$. Only

Table I: One-way sensitivity analysis.

\begin{tabular}{lcc}
\hline Study excluded & \multicolumn{2}{c}{ Random effects model } \\
\hline & Odds ratio & $99 \% \mathrm{Cl}$ \\
Wendland et al[59] & 1.03 & $0.72-1.48$ \\
England et al. [24] & 0.94 & $0.84-1.06$ \\
Xiong et al. [60] & 0.95 & $0.85-1.07$ \\
Rodrigues et al. Cree [66] & 0.96 & $0.85-1.07$ \\
Rodrigues et al. Non-native [66] & 0.95 & $0.85-1.07$
\end{tabular}

two studies $[23,58]$ presented comparable categories for heavy smokers (more than $10 \mathrm{cig} /$ day). In a random effects model, given that significant heterogeneity was present $(Q=5.66 ; \mathrm{p}=0.06)$, similar results were found for women that smoked 10 or more than cigarettes per day during pregnancy $(\mathrm{OR}=0.72 ; 99 \% \mathrm{CI} 0.37-1.42)$.

The Egger's test provided no evidence of publication bias for the unadjusted ( $\mathrm{p}=0.31$ ) or adjusted ( $\mathrm{p}=0.92)$ overall associations of smoking with gestational diabetes. In the sensitivity analysis, the overall heterogeneity and association size were recalculated by iteratively removing one study at a time. This analysis confirmed the stability of the summary risk estimate (Additonal File 2).

\section{Discussion}

Cigarette smoking has been considered as a risk factor for diabetes outside of pregnancy $[20,71]$ and as such, could also be seen as a risk factor for gestational diabetes [24,37]. However, our meta-analysis does not support the 


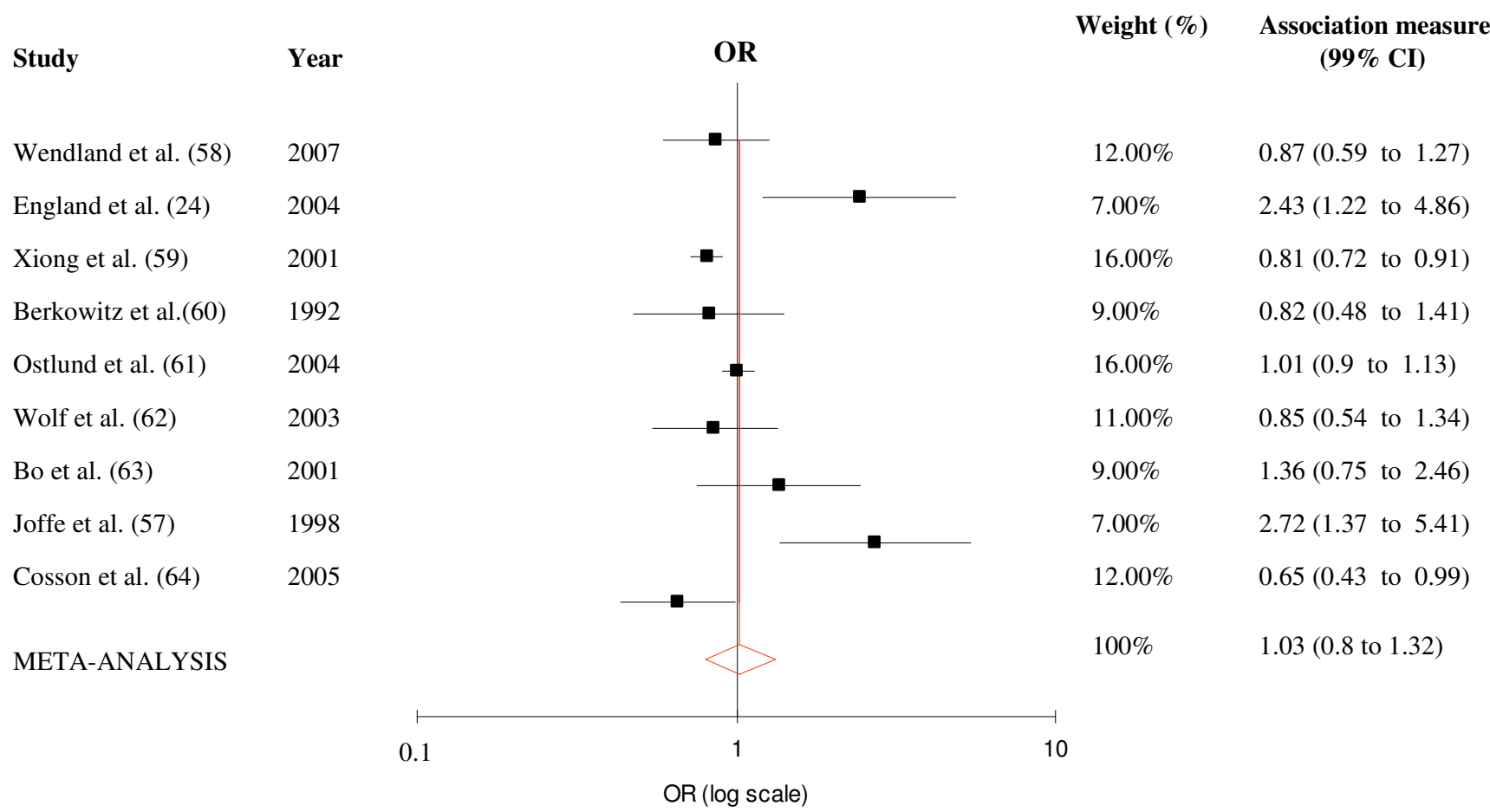

Figure 2

Meta-analysis of unadjusted results of studies of the association between smoking and gestational diabetes. Black squares indicate the odds ratio in each study and the horizontal lines represent $99 \%$ confidence intervals. Random-effects model.

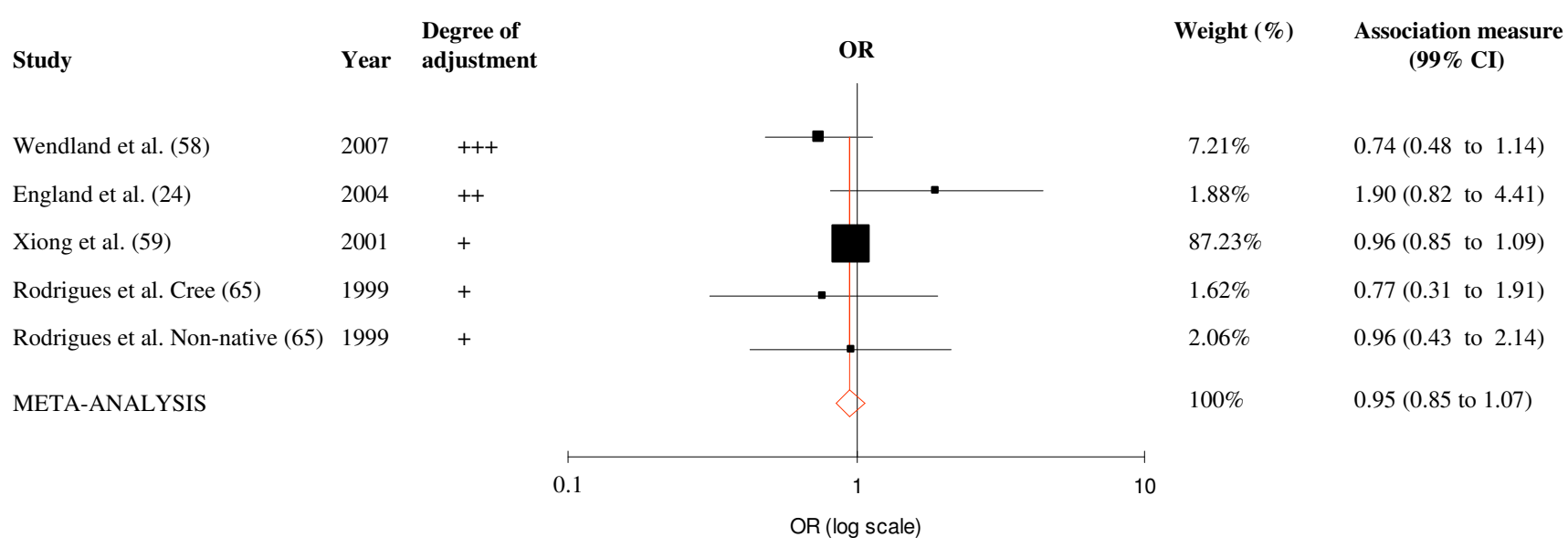

Figure 3

Meta-analysis of adjusted results of studies of the association between smoking during pregnancy and gestational diabetes. Black squares indicate the odds ratio in each study, with the square size proportional to the weight of the study in the meta-analysis and the horizontal lines represent $99 \%$ confidence intervals. Fixed-effects model. 
hypothesis that smoking during pregnancy increases the risk of gestational diabetes.

To our knowledge, this is the first systematic review and meta-analysis evaluating the association of smoking during pregnancy and gestational diabetes. Although we found a great diversity in the assessment of outcomes and adjustment for confounding variables, sensitivity analysis did not reveal an important influence of any single study (Additonal File 2). As our results are based on published studies only, other small studies describing a null association may have escaped identification.

The evidence published so far for the association between smoking and gestational diabetes is inconsistent $[23,24,60,66]$. How to reconcile these differences is not clear. It is possible that differences between the study settings such as screening procedures for GDM, or due to variations in the content of cigarettes [72] or in the frequency of stopping smoking during pregnancy may explain this inconsistency. Lumping ex-smokers with never smokers could raise the risk in this comparison group, producing an apparent lower risk in smokers. However the only two studies explicitly reporting data on quitters in the adjusted models showed inconsistent results $[59,73]$.

One such difference meriting special consideration is the moment of measuring smoking during pregnancy. Smoking cessation or reduction in the number of cigarettes smoked during pregnancy accentuates gestational weight gain [74], an important risk factor for gestational diabetes [75]. Thus, failure to identify smokers who quit after ascertainment or who reduced the number of cigarettes smoked during pregnancy may lead to information bias, erroneously attributing the association found to smoking rather than to its reduction. Furthermore, social pressure to quit smoking may lead to erratic smoking behavior during pregnancy, difficult to access in epidemiologic studies [76]. In this regard, our meta-analysis of reports that assessed smoking earlier in pregnancy $[24,57,62,63,65]$ showed a tendency to present an increased risk of developing gestational diabetes, while our meta-analysis of studies that ascertained smoking later in pregnancy, and thus possibility more accurately, [59-61,66] showed odds ratios slightly less than 1 .

Our study illustrates the difficulties of systematic reviews of observational studies. We identified a variety of definitions in the ascertainment of gestational diabetes and part of the variation in the results between studies may be related to this variation. Moreover, the degree of information in the reports is frequently less than desirable. Aspects such as characteristics of the population, definitions of exposures and of diagnostic procedures and thus outcomes, statistical analysis routines and measures of association are not systematically described in the reports, limiting the comparability of the studies and utility of some of the extracted data. The inclusion of two studies $[24,57]$ referring to the same population in the crude analysis may have biased the crude estimate slightly upward. However, this does not appear to have been an important problem as the adjusted analysis, in which only one of these studies was included, showed a similar result.

Other limitations of the present meta-analysis must be considered. The small number of reports published did not allow us to do extensive sensitivity nor subgroup analyses. Another potential limitation, as previously mentioned, is information bias with respect to categorization of cigarette smoking, as all studies were based on a limited assessment by self-reports of smoking habits. As women in general tend to under-report smoking during pregnancy by about $15 \%$ [77], non-differential misclassification could bias the results to the null.

\section{Conclusion}

Current data demonstrate important heterogeneity and, when taken together, do not support an association between cigarette smoking during pregnancy and the risk of gestational diabetes. Further research with more detailed and objective measurements of smoking is needed to evaluate this association. In vitro and animal studies may further help to clarify possible biologic mechanisms and pathways by which cigarette smoking may play a role in the development of gestational diabetes.

\section{Competing interests}

The authors declare that they have no competing interests.

\section{Authors' contributions}

EMW carried out the search, acquisition and interpretation of the data in studies, performed the statistical analysis and drafted the manuscript. MEP participated in the selection of studies; MIS participated in design of the study, selection of studies and manuscript preparation; BBD participated in the design of the study and manuscript preparation; JMB participated in the final version of the study. All authors read and approved the final manuscript.

\section{Additional material}

\section{Additional file 1}

Characteristics of studies of the association of cigarette smoking and gestational diabetes mellitus.

Click here for file

[http://www.biomedcentral.com/content/supplementary/14712393-8-53-S1.doc] 


\section{Additional file 2}

Summary of study diagnostic process characteristics and associations found between smoking and gestational diabetes.

Click here for file

[http://www.biomedcentral.com/content/supplementary/14712393-8-53-S2.doc]

\section{Acknowledgements}

CAPES Foundation - Ministry of Education - Brazil.

\section{References}

I. Metzger BE, Coustan DR: Summary and recommendations of the Fourth International Workshop-Conference on Gestational Diabetes Mellitus. The Organizing Committee. Diabetes Care 1998, 2 I(Suppl 2):BI6I-BI67.

2. King $\mathrm{H}$ : Epidemiology of glucose intolerance and gestational diabetes in women of childbearing age. Diabetes Care 1998, 2I(Suppl 2):B9-13.

3. Schmidt MI, Duncan BB, Reichelt AJ, Branchtein L, Matos MC, Costa e Forti, et al.: Gestational diabetes mellitus diagnosed with a 2h 75-g oral glucose tolerance test and adverse pregnancy outcomes. Diabetes Care 200 I, 24: II5I-II 55.

4. Dabelea D, Snell-Bergeon JK, Hartsfield CL, Bischoff KJ, Hamman RF, McDuffie RS: Increasing prevalence of gestational diabetes mellitus (GDM) over time and by birth cohort: Kaiser Permanente of Colorado GDM Screening Program. Diabetes Care 2005, 28:579-584.

5. Jarrett RJ, Castro-Soares J, Dornhorst A, Beard RW, Castro-Soares J: Should we screen for gestational diabetes? BMJ 1997, 3 1 5:736-739.

6. Sermer M, Naylor CD, Farine D, Kenshole AB, Ritchie JW, Gare DJ, et al.: The Toronto Tri-Hospital Gestational Diabetes Project. A preliminary review. Diabetes Care 1998, 2 I(Suppl 2):B33-B42.

7. Jacob Reichelt AA, Ferraz TM, Rocha Oppermann ML, Costa e Forti, Duncan BB, Fleck PE, et al.: Detecting glucose intolerance after gestational diabetes: inadequacy of fasting glucose alone and risk associated with gestational diabetes and second trimester waist-hip ratio. Diabetologia 2002, 45:455-457.

8. Cheung NW, Byth K: Population health significance of gestational diabetes. Diabetes Care 2003, 26:2005-2009.

9. Naylor CD, Sermer M, Chen E, Farine D: Selective screening for gestational diabetes mellitus. Toronto Trihospital Gestational Diabetes Project Investigators. N Engl J Med 1997, 337: $159 \mid-1596$.

10. Davey RX, Hamblin PS: Selective versus universal screening for gestational diabetes mellitus: an evaluation of predictive risk factors. Med J Aust 200I, 174:118-121.

II. Alberti KG, Zimmet PZ: Definition, diagnosis and classification of diabetes mellitus and its complications. Part I: diagnosis and classification of diabetes mellitus provisional report of a WHO consultation. Diabet Med 1998, 1 5:539-553.

12. CDC: Smoking during pregnancy - United States, 19902002. MMWR Morb Mortal Wkly Rep 2004, 53:9II-9I5.

13. ACOG educational bulletin. Smoking and women's health. Number 240, September 1997 (Replaces No. 180, May 1993). American College of Obstetricians and Gynecologists. Int J Gynaecol Obstet 1998, 60:7I-82.

14. Kaneita Y, Tomofumi S, Takemura S, Suzuki K, Yokoyama E, Miyake $\mathrm{T}$, et al: Prevalence of smoking and associated factors among pregnant women in Japan. Prev Med 2007, 45:15-20.

15. Ward C, Lewis S, Coleman T: Prevalence of maternal smoking and environmental tobacco smoke exposure during pregnancy and impact on birth weight: retrospective study using Millennium Cohort. BMC Public Health 2007, 7:81.

16. Kroeff LR, Mengue SS, Schmidt MI, Duncan BB, Favaretto AL, Nucci LB: [Correlates of smoking in pregnant women in six Brazilian cities]. Rev Saude Publica 2004, 38:26I-267.
17. Castles A, Adams EK, Melvin CL, Kelsch C, Boulton ML: Effects of smoking during pregnancy. Five meta-analyses. Am J Prev Med 1999, 16:208-215.

18. U.S. Department of Health and Human Services: Women and smoking: A report of the Surgeon General. Rockville, MD: U.S. Dept. of Health and Human Services, Public Health Service, Office of the Surgeon General; 200I.

19. Oken E, Huh SY, Taveras EM, Rich-Edwards JW, Gillman MW: Associations of maternal prenatal smoking with child adiposity and blood pressure. Obes Res 2005, 13:2021-2028.

20. Rimm EB, Manson JE, Stampfer MJ, Colditz GA, Willett WC, Rosner $B$, et al:: Cigarette smoking and the risk of diabetes in women. Am J Public Health 1993, 83:2। I-214.

21. Will JC, Galuska DA, Ford ES, Mokdad A, Calle EE: Cigarette smoking and diabetes mellitus: evidence of a positive association from a large prospective cohort study. Int J Epidemiol 200I, 30:540-546.

22. Meigs JB, Nathan DM, Cupples LA, Wilson PW, Singer DE: Tracking of glycated hemoglobin in the original cohort of the Framingham Heart Study. J Clin Epidemiol 1996, 49:4I I-4I7.

23. Terry PD, Weiderpass E, Ostenson CG, Cnattingius S: Cigarette smoking and the risk of gestational and pregestational diabetes in two consecutive pregnancies. Diabetes Care 2003, 26:2994-2998.

24. England LJ, Levine RJ, Qian C, Soule LM, Schisterman EF, Yu KF, et al.: Glucose tolerance and risk of gestational diabetes mellitus in nulliparous women who smoke during pregnancy. Am J Epidemiol 2004, 160:1205-1213.

25. Conde-Agudelo A, Althabe F, Belizan JM, Kafury-Goeta AC: Cigarette smoking during pregnancy and risk of preeclampsia: a systematic review. Am J Obstet Gynecol 1999, I 81: 1026-1035.

26. Thomas GA, Rhodes J, Ingram JR: Mechanisms of disease: nicotine - a review of its actions in the context of gastrointestinal disease. Nat Clin Pract Gastroenterol Hepatol 2005, 2:536-544.

27. Thacker EL, O'Reilly EJ, Weisskopf MG, Chen H, Schwarzschild MA, McCullough ML, et al.: Temporal relationship between cigarette smoking and risk of Parkinson disease. Neurology 2007, 68:764-768.

28. Stroup DF, Berlin JA, Morton SC, Olkin I, Williamson GD, Rennie D, et al.: Meta-analysis of observational studies in epidemiology: a proposal for reporting. Meta-analysis Of Observational Studies in Epidemiology (MOOSE) group. JAMA 2000, 283:2008-20I2.

29. Richter B, Bergerhoff K, Paletta G, Bandeira-Echtler E: Metabolic and Endocrine Disorders Group. 2007.

30. The Editorial Team: Pregnancy and Childbirth Group. Issue 4 edn 2007.

31. Lancaster T, Stead T, Cahill K, West R, Aveyard P, Hughes J: Tobacco Addiction Group. Issue 4 edn 2007.

32. Olsen O, Shea B, Wells G: Extracting data. 2005, Chapter 5:

33. Bax L, Yu LM, Ikeda N, Tsuruta H, Moons KG: Development and validation of MIX: comprehensive free software for metaanalysis of causal research data. BMC Med Res Methodol 2006, 6:50.

34. DerSimonian R, Laird N: Meta-analysis in clinical trials. Control Clin Trials 1986, 7:177-188.

35. Egger M, Davey SG, Schneider M, Minder C: Bias in meta-analysis detected by a simple, graphical test. BM] 1997, 3 I5:629-634.

36. NHMRC: How to review the evidence: systematic identification and review of the scientific literature. 1999.

37. Solomon CG, Willett WC, Carey VJ, Rich-Edwards J, Hunter DJ, Colditz GA, et al:: A prospective study of pregravid determinants of gestational diabetes mellitus. JAMA 1997, 278: $1078-1083$

38. Retnakaran R, Hanley AJ, Raif N, Connelly PW, Sermer M, Zinman B: $C$-reactive protein and gestational diabetes: the central role of maternal obesity. J Clin Endocrinol Metab 2003, 88:3507-35 I2.

39. Heckbert SR, Stephens CR, Daling JR: Diabetes in pregnancy: maternal and infant outcome. Paediatr Perinat Epidemiol 1988, 2:3|4-326.

40. Rudra CB, Williams MA, Lee IM, Miller RS, Sorensen TK: Perceived exertion in physical activity and risk of gestational diabetes mellitus. Epidemiology 2006, 17:3I-37.

4I. Yang X, Hsu-Hage B, Zhang H, Yu L, Dong L, Li J, et al.: Gestational diabetes mellitus in women of single gravidity in Tianjin City, China. Diabetes Care 2002, 25:847-85।. 
42. Kieffer EC, Sinco B, Kim C: Health behaviors among women of reproductive age with and without a history of gestational diabetes mellitus. Diabetes Care 2006, 29:1788-1793.

43. van Hoorn J, Dekker G, Jeffries B: Gestational diabetes versus obesity as risk factors for pregnancy-induced hypertensive disorders and fetal macrosomia. Aust N ZJ Obstet Gynaecol 2002, 42:29-34.

44. Goldman JA, Schechter A: Effect of cigarette smoking on glucose tolerance in pregnant women. Isr J Med Sci 1967, 3:561-564

45. Langhoff-Roos J, Wibell L, Gebre-Medhin M, Lindmark G: Effect of smoking on maternal glucose metabolism. Gynecol Obstet Invest 1993, 36:8-II.

46. Zaren B, Lindmark G, Wibell L, Folling I: The effect of smoking on glucose homeostasis and fetal growth in pregnant women. Ups J Med Sci 2000, 105:4I-56.

47. Saldana TM, Siega-Riz AM, Adair LS: Effect of macronutrient intake on the development of glucose intolerance during pregnancy. Am J Clin Nutr 2004, 79:479-486.

48. Gohdes D, Oser CS, Harwell TS, Moore KR, McDowall JM, Helgerson SD: Diabetes in Montana's Indians: the epidemiology of diabetes in the Indians of the Northern Plains and Canada. Curr Diab Rep 2004, 4:224-229.

49. Dornhorst $A$, Rossi M: Risk and prevention of type 2 diabetes in women with gestational diabetes. Diabetes Care 1998, 2 I (Suppl 2):B43-B49.

50. Nylund L, Lunell NO, Persson B, Fredholm BB, Lagercrantz $H$ : Smoking exerts a ketogenic influence in diabetic pregnancy. Gynecol Obstet Invest 1988, 25:35-37.

5I. Ros HS, Cnattingius S, Lipworth L: Comparison of risk factors for preeclampsia and gestational hypertension in a populationbased cohort study. Am J Epidemiol 1998, 147:1062-1070.

52. Montgomery SM, Ekbom A: Smoking during pregnancy and diabetes mellitus in a British longitudinal birth cohort. BMJ 2002 324:26-27.

53. Caulfield LE, Harris SB, Whalen EA, Sugamori ME: Maternal nutritional status, diabetes and risk of macrosomia among Native Canadian women. Early Hum Dev 1998, 50:293-303.

54. Rosenberg MS: The file-drawer problem revisited: a general weighted method for calculating fail-safe numbers in metaanalysis. Evolution 2005, 59(2):464-468.

55. Bottini E, Gloria-Bottini F, La Torre M, Lucarini N: The genetics of signal transduction and the effect of smoking on intrauterine growth. Int J Epidemiol 200I, 30:400-402.

56. Dempsey JC, Butler CL, Sorensen TK, Lee IM, Thompson ML, Miller $\mathrm{RS}$, et al.: A case-control study of maternal recreational physical activity and risk of gestational diabetes mellitus. Diabetes Res Clin Pract 2004, 66:203-2I5.

57. Joffe GM, Esterlitz JR, Levine RJ, Clemens JD, Ewell MG, Sibai BM, et al.: The relationship between abnormal glucose tolerance and hypertensive disorders of pregnancy in healthy nulliparous women. Calcium for Preeclampsia Prevention (CPEP) Study Group. Am J Obstet Gynecol 1998, I79:1032-I037.

58. Cnattingius $S$, Lambe $M$ : Trends in smoking and overweight during pregnancy: prevalence, risks of pregnancy complications, and adverse pregnancy outcomes. Semin Perinatol 2002, 26:286-295

59. Wendland EM: $\mathbf{O}$ hábito de fumar e o risco de desenvolver diabetes e hipertensão durante a gestação. In Graduate Studies Program in Epidemiology Federal University of Rio Grande do Sul. Brazil; PhD thesis; 2007.

60. Xiong X, Saunders LD, Wang FL, Demianczuk NN: Gestational diabetes mellitus: prevalence, risk factors, maternal and infant outcomes. Int J Gynaecol Obstet 200I, 75:22I-228.

61. Berkowitz GS, Lapinski RH, Wein R, Lee D: Race/ethnicity and other risk factors for gestational diabetes. Am J Epidemiol 1992 I 35:965-973.

62. Ostlund I, Haglund B, Hanson U: Gestational diabetes and preeclampsia. Eur J Obstet Gynecol Reprod Biol 2004, I I 3:12-16.

63. Wolf M, Sandler L, Hsu K, Vossen-Smirnakis K, Ecker JL, Thadhani R First-trimester $C$-reactive protein and subsequent gestational diabetes. Diabetes Care 2003, 26:819-824.

64. Bo S, Menato G, Lezo A, Signorile A, Bardelli C, De Michieli F, et al.: Dietary fat and gestational hyperglycaemia. Diabetologia 200I, 44:972-978.
65. Cosson E, Benchimol M, Carbillon L, Pharisien I, Paries J, Valensi P, et al: Universal rather than selective screening for gestational diabetes mellitus may improve fetal outcomes. Diabetes Metab 2006, 32:|40-|46.

66. Rodrigues S, Robinson EJ, Ghezzo H, Gray-Donald K: Interaction of body weight and ethnicity on risk of gestational diabetes mellitus. Am J Clin Nutr 1999, 70: 1083-1089.

67. Xiong X, Wang FL, Davidge ST, Demianczuk NN, Mayes DC, Olson DM, et al: Maternal smoking and preeclampsia. I Reprod Med 2000, 45:727-732.

68. Rodrigues S, Robinson E, Gray-Donald K: Prevalence of gestational diabetes mellitus among James Bay Cree women in northern Quebec. CMAJ 1999, 160:1293-1297.

69. Wendland EM, Duncan BB, Mengue SS, Nucci LB, Schmidt MI: Waist circumference in the prediction of obesity-related adverse pregnancy outcomes. Cad Saude Publica 2007, 23:39I-398.

70. Cnattingius S: The epidemiology of smoking during pregnancy: smoking prevalence, maternal characteristics, and pregnancy outcomes. Nicotine Tob Res 2004, 6(Suppl 2):SI25-SI40.

7I. Wannamethee SG, Shaper AG, Perry IJ: Smoking as a modifiable risk factor for type 2 diabetes in middle-aged men. Diabetes Care 200I, 24:1590-I595.

72. Dooley MA, Hogan SL: Environmental epidemiology and risk factors for autoimmune disease. Curr Opin Rheumatol 2003, 15:99-103.

73. England LJ, Levine RJ, Qian C, Morris CD, Sibai BM, Catalano PM, et al.: Smoking before pregnancy and risk of gestational hypertension and preeclampsia. Am J Obstet Gynecol 2002, 186: $1035-1040$

74. Favaretto AL, Duncan BB, Mengue SS, Nucci LB, Barros EF, Kroeff LR, et al.: Prenatal weight gain following smoking cessation. Eur J Obstet Gynecol Reprod Biol 2007.

75. Kabiru W, Raynor BD: Obstetric outcomes associated with increase in BMI category during pregnancy. Am J Obstet Gynecol 2004, I $91: 928-932$

76. Pickett KE, Wakschlag LS, Dai L, Leventhal BL: Fluctuations of maternal smoking during pregnancy. Obstet Gynecol 2003, I0I:140-147.

77. Klebanoff MA, Levine RJ, Morris CD, Hauth JC, Sibai BM, Ben Curet $\mathrm{L}$, et al:: Accuracy of self-reported cigarette smoking among pregnant women in the 1990s. Paediatr Perinat Epidemiol 2001, I5:140-143.

\section{Pre-publication history}

The pre-publication history for this paper can be accessed here:

http://www.biomedcentral.com/1471-2393/8/53/prepub
Publish with Bio Med Central and every scientist can read your work free of charge

"BioMed Central will be the most significant development for disseminating the results of biomedical research in our lifetime. "

Sir Paul Nurse, Cancer Research UK

Your research papers will be:

- available free of charge to the entire biomedical community

- peer reviewed and published immediately upon acceptance

- cited in PubMed and archived on PubMed Central

- yours - you keep the copyright
BioMedcentral 